\title{
Interação oral em Português Língua Estrangeira: preparação significativa a partir de necessidades comunicativas
}

\author{
Ângela Carvalho \\ Faculdade de Letras da Universidade do Porto \\ Centro de Linguística da Universidade do Porto, Portugal \\ accarvalho@letras.up.pt \\ Isabel Margarida Duarte \\ Faculdade de Letras da Universidade do Porto \\ Centro de Linguística da Universidade do Porto, Portugal \\ iduarte@letras.up.pt
}

\section{Resumo}

A prática quotidiana na aula mostra ser preciso refletir sobre abordagens didáticas que articulem variáveis cognitivas e emocionais, "para além da tarefa". Urge conhecer interesses e necessidades dos aprendentes, envolvê-los nas suas aprendizagens, enquadradas em propostas amplas, tornando-as significativas. Estas propostas devem fomentar o saber trabalhar com o Outro, em dinâmicas equilibradas e motivadoras, interpeladoras das identidades culturais e afetivas dos estudantes, a partir das suas representações sobre a(s) língua(s)/cultura(s)-alvo e a comunidade onde estão a aprendê-la. Relataremos uma experiência efetuada no seio de uma turma de nível A2 de Português Língua Estrangeira, em que partimos da reflexão dos aprendentes sobre as suas necessidades comunicativas, para propostas de atividades em grupo que visavam o contacto com falantes nativos em diferentes serviços, a construção de material didático pelos estudantes, decorrente da atividade anterior, assim como a simulação de situações nos cenários em foco.

Palavras-chave: Português Língua Estrangeira, Ensino de Línguas Baseado em Tarefas, projeto, interação oral 
CARVALHO, Ângela; Duarte, Isabel Margarida - Interação oral em Português Língua Estrangeira: preparação significativa a partir de necessidades comunicativas

Para lá da tarefa: implicar os estudantes na aprendizagem de línguas estrangeiras no ensino superior. Porto: FLUP, 2019, pp. 116-134 DOI: https://doi.org/10.21747/9789898969217/paraa6

\begin{abstract}
Our daily practice in the classroom shows that it is necessary to reflect on didactic approaches that articulate cognitive and emotional variables, "beyond the task". We urgently need to know the interests and needs of the learners, to involve them in their learning, framed in broad proposals, making them meaningful to them. These proposals should foster the ability to work with the Other in balanced and motivating dynamics that challenge students' cultural and affective identities, based on their representations about the target language (s) / culture (s) and community where they are learning it. We will report on an experiment carried out in a group of $\mathrm{A} 2$ level of Portuguese as a Foreign Language, in which we start from the reflection of the learners about their communicative needs, for proposals of group activities that aimed at contact with native speakers in different services, the construction of educational material by the students, resulting from the previous activity, as well as the simulation of situations in the scenarios in focus.
\end{abstract}

Keywords: Portuguese as a foreign language, Tasks based learning, Project work, oral interaction

\title{
1 - Introdução
}

O ensino de línguas estrangeiras recebeu um impulso inegável com a corrente a que chamamos Ensino de Línguas Baseado em Tarefas (ELBT), ao passar de um modelo focado na forma, assente na realização de exercícios gramaticais (Richards \& Rodgers, 2001) para um modelo que adota a tarefa final como o eixo do desenho de uma unidade temática, assim como do próprio processo de ensino-aprendizagem, determinando a seleção de conteúdos, materiais, estratégias e competências em foco, bem como enformando a planificação didática (Estaire \& Zanón, 1990).

Os contributos desta corrente para o ensino da Língua Portuguesa têm sido vários e sugerem os mesmos bons resultados alcançados para outras línguas (p.e., Castro \& Grosso, 2017, Pinto, 2011).

No entanto, para que as tarefas sejam eficazes em termos de aprendizagem de línguas, terão de ser significativas para os estudantes e de ter um caráter tão autêntico quanto possível, apresentando-se como representativas dos aspetos da comunicação da vida real. De acordo com Nunan (2004), o ELBT é uma abordagem que parte das necessidades dos alunos para a seleção de conteúdos, que estabelece uma ponte entre a aprendizagem de sala de aula e a língua usada fora da mesma. Na proposta que faremos, não é apenas a língua usada fora da aula que entra dentro dela, em 
CARVALHO, Ângela; Duarte, Isabel Margarida - Interação oral em Português Língua Estrangeira: preparação significativa a partir de necessidades comunicativas

Para lá da tarefa: implicar os estudantes na aprendizagem de línguas estrangeiras no ensino superior. Porto: FLUP, 2019, pp. 116-134 DOI: https://doi.org/10.21747/9789898969217/paraa6

documentos reais vários. São também os alunos que saiem da sala e vão à procura do contacto com a língua que se fala fora da aula, assim aumentando e enriquecendo o input linguístico que recebem.

Esta prática decorre do facto de se acreditar que a aprendizagem de uma língua "depend in immersing students not merely in 'comprehensible input' but in tasks that require them to negotiate meaning and engage in naturalistic and meaningful communication" (Richards \& Rodgers, 2001, pp. 223-224).

A prática quotidiana na aula mostra ser preciso refletir sobre abordagens didáticas que articulem variáveis cognitivas e emocionais, "para além da tarefa". Urge conhecer interesses e necessidades dos aprendentes, as representações que têm da língua-alvo e da sua aprendizagem, envolvê-los nessas aprendizagens, enquadradas em propostas amplas, tornando-as significativas para eles, como Perrenoud (1995) propôs, ao sugerir que se encontre um sentido para o trabalho escolar dos alunos. Estas propostas devem fomentar o saber trabalhar com o Outro, em dinâmicas equilibradas e motivadoras, interpeladoras das identidades culturais e afetivas dos estudantes, a partir das suas representações sobre a(s) língua(s)/cultura(s)-alvo e a comunidade onde estão a aprendê-la(s). Elas devem, em suma, promover o desenvolvimento da competência comunicativa intercultural (Byram, 1997). Importa aqui referir a relevância do desenho de propostas adequadas às competências e proficiência dos aprendentes, no sentido em que sejam exequíveis mas desafiantes, permitindo um progresso alicerçado, natural e estimulante para o aluno (Vygotsky, 1978). Por outras palavras: as tarefas deverão estar articuladas em projetos que façam sentido e envolvam linguística, cultural e emocionalmente os estudantes. Um primeiro passo para que sintam o trabalho como significativo é que ele corresponda às necessidades comunicativas que são as suas. Por isso, a experiência que se apresenta e sobre que agora se reflete começou pelo levantamento das situações comunicativas que, segundo a perceção dos estudantes, eles precisavam de dominar e com mais urgência. $O$ trabalho colaborativo foi outra aposta, por acreditarmos ser mais motivador e ajudar a derrubar barreiras e estereótipos culturais, promovendo a comunicação e a partilha, e contrariando a tendência para a concorrência e a emulação.

Neste artigo, relataremos a experiência efetuada com uma turma heterogénea de nível A2 de Português Língua Estrangeira (PLE) da Faculdade de Letras da Universidade do Porto (FLUP), composta por 15 estudantes, do ano letivo 2017-2018, a aprender português, portanto, em contexto de imersão linguística. O curso em causa tinha 60 horas e cerca de 4 meses de extensão (4 horas semanais). 
CARVALHO, Ângela; Duarte, Isabel Margarida - Interação oral em Português Língua Estrangeira: preparação significativa a partir de necessidades comunicativas

Para lá da tarefa: implicar os estudantes na aprendizagem de línguas estrangeiras no ensino superior. Porto: FLUP, 2019, pp. 116-134 DOI: https://doi.org/10.21747/9789898969217/paraa6

Partimos da representação e da reflexão dos aprendentes sobre as suas necessidades comunicativas, para desenharmos propostas de tarefas em grupo. Eis os objetivos dessas tarefas: (i) o contacto com falantes nativos em diferentes serviços, (ii) a construção de material didático pelos próprios estudantes, decorrente da atividade anterior, (iii) a simulação de situações nos cenários em foco, (iv) a prática da oralidade, assim como (v) a análise e reflexão sobre discurso autêntico, oral e espontâneo.

Os nossos objetivos, com este artigo, são, portanto:

1. refletir sobre a importância de articular as tarefas em função de um projeto significativo para os estudantes, integrando atividades de sala de aula e fora dela, de forma planeada e articulada;

2. relatar duas tarefas de uma experiência de projeto concreto, refletindo criticamente sobre as mesmas;

3. mostrar como os estudantes aprenderam língua através da concretização do projeto.

Sendo a pedagogia de projeto regida por princípios como intencionalidade, flexibilidade, originalidade e interdisciplinaridade (Perrenoud, 1999), só o último não foi tido em conta nesta experiência, devido ao contexto específico em que ela decorreu: em aulas do Curso Anual de Português para Estrangeiros da FLUP. Contrariamente ao uso descontextualizado das tarefas, se forem enquadradas num projeto, elas adquirem, obviamente, uma intencionalidade: a do seu concurso para a conclusão do projeto, usando a língua portuguesa. A flexibilidade é essencial para que o projeto seja levado a bom porto: quer a que decorre das vicissitudes próprias do trabalho colaborativo entre os aprendentes, que têm de se ajustar uns aos outros, quer a que provém das decisões refletidas do docente, mediante o caminho de aprendizagem que é feito, a cada momento, pelos estudantes e que o professor tem de permanentemente monitorizar, reequacionar, adaptar e avaliar. O professor precisa de, em face das necessidades que vão sendo demonstradas, alterar percursos e materiais, parar e explicitar conteúdos ou tarefas. Por fim: cada projeto é diferente dos outros, dependendo dos sujeitos que lhe dão corpo, dos seus interesses, das suas interações próprias, do nível de proficiência que revelam, das dinâmicas que entre eles criam, dos temas eleitos, das línguas / culturas que são as suas, etc.

No que toca à produção, como Vera e Blanco (2014, pp. 131-132) notam, grande parte das atividades usadas para desenvolver a competência discursiva oral na aula, 
CARVALHO, Ângela; Duarte, Isabel Margarida - Interação oral em Português Língua Estrangeira: preparação significativa a partir de necessidades comunicativas

Para lá da tarefa: implicar os estudantes na aprendizagem de línguas estrangeiras no ensino superior. Porto: FLUP, 2019, pp. 116-134 DOI: https://doi.org/10.21747/9789898969217/paraa6

tratan de reproducir (mediante cierta forma de dramatización), situaciones habituales de comunicación que tienen lugar en la vida real [...], de tal manera que los alumnos representan en ellas roles sociales que tienen que adecuarse a las restricciones pragmáticas propias de la lengua en cuestión en tales situcaiones comunicativas.

Para comunicar, não basta, portanto, conhecer as regras do sistema da língua: é fundamental conhecer a língua em uso, com a variação que lhe é inerente.

Vejamos, então, como decorreu o projeto referido, centrado no desenvolvimento da interação oral em português.

\section{2 - Descrição refletida da primeira tarefa proposta}

$\mathrm{Na}$ segunda aula, de um total de 30 , os alunos tiveram, como trabalho de casa, de pensar em quais as situações comunicativas do dia a dia que gostariam de abordar preferencialmente, no âmbito das aulas de PLE, dado que então viviam, por um período maior ou menor de tempo, em Portugal. Esta reflexão decorreu na sequência de terem trabalhado, em aula, a situação comunicativa de aquisição de um bilhete de comboio a partir de uma banda desenhada de produção própria1. Na aula número 3, os estudantes falaram das suas preferências e urgências, explicando quais os contextos comunicativos que gostariam de abordar. A partir desta apresentação refletida de necessidades e preferências, da ficha de identificação que tinham já preenchido na primeira aula e da observação da exequibilidade das várias propostas, a professora a cargo da turma selecionou 5 situações que apresentou na aula número 8 , assim como as instruções da tarefa a realizar a esse propósito. Entre a aula 2 e a aula 8, foram trabalhados vários aspetos linguísticos, bem como temáticos, nomeadamente registos de língua e profissões tradicionais, que puderam servir de apoio, mais tarde, para as tarefas a executar, nomeadamente pela familiarização com aspetos que poderiam causar obstáculo à realização das tarefas propostas.

Os cenários comunicativos foram apresentados na aula, e os alunos tiveram de se enquadrar num deles, agrupando-se segundo o interesse pelo tema, não tendo sido apresentado qualquer constrangimento de agrupamento dos estudantes em função da respetiva Língua Materna, o que tinha sido prática comum em atividades anteriores de pares e grupos. Eis as diversas interações propostas:

a) Interação numa loja (deveriam escolher o tipo de loja)

\footnotetext{
${ }^{1}$ Da autoria de Salomé Girard.
} 
CARVALHO, Ângela; Duarte, Isabel Margarida - Interação oral em Português Língua Estrangeira: preparação significativa a partir de necessidades comunicativas Para lá da tarefa: implicar os estudantes na aprendizagem de línguas estrangeiras no ensino superior. DOI: https://doi.org/10.21747/9789898969217/paraa6

b) Interação num restaurante

c) Interação num cabeleireiro

d) Interação num hotel (deveriam escolher um cenário comunicativo mais específico)

e) Interação para pedir informações sobre um arrendamento e visita a uma casa/um quarto.

Foi indicado que os alunos deveriam começar o trabalho fora da sala de aula e concluí-lo até no máximo 10 dias depois, durante a aula número 10, em que teriam também de o apresentar oralmente à turma.

As instruções pormenorizadas foram enviadas aos estudantes por email:

"Para o dia 23 têm o trabalho que hoje acordámos na aula - só uma situação por grupo de alunos.
a) Interação numa loja (devem escolher o tipo de loja): Alunas A e B
b) Interação num restaurante: Alunas $C, D$ e $E$
c) Interação num cabeleireiro: Alunas F, G e H
d) Interação num hotel (devem escolher a situação mais específica): Alunos I, J e K

e) Interação numa situação de pedir informações sobre um arrendamento e visita a uma casa/um quarto: Alunos L e M

Cada grupo deve indicar:

- Vocabulário específico da situação com explicação simples em português (no máximo 10, as mais importantes); nomes.

Exemplo para o médico: estetoscópio - instrumento para auscultar a respiração e as batidas do coração

- Ações principais (no máximo 8, as mais importantes); verbos.

Exemplo para o médico: diagnosticar (uma doença)

- Frases úteis (máximo 5, as mais importantes)

Exemplo para o médico: Há quantos dias tem estes sintomas?

- Diálogo modelo. O diálogo não tem um limite de palavras, mas deve ser uma conversa com início, meio e fim.

No dia 23 vou dar uns minutos iniciais para concluir o trabalho, mas a maior parte do trabalho já deve estar feita.

Depois têm de me mandar o trabalho por email, em Word, para eu corrigir e fotocopiar um exemplar para cada aluno." 
CARVALHO, Ângela; Duarte, Isabel Margarida - Interação oral em Português Língua Estrangeira: preparação significativa a partir de necessidades comunicativas

Para lá da tarefa: implicar os estudantes na aprendizagem de línguas estrangeiras no ensino superior. Porto: FLUP, 2019, pp. 116-134 DOI: https://doi.org/10.21747/9789898969217/paraa6

Como se pode verificar pela leitura das indicações enviadas por email, para a consecução de cada tarefa, cada grupo deveria indicar qual o léxico mais significativo específico da situação comunicativa a trabalhar, com uma explicação simples sobre o significado de cada palavra, em português, num máximo de dez nomes. Dentro ainda do trabalho com o léxico, cada grupo deveria propor verbos, traduzindo algumas das ações principais características da situação comunicativa preparada Assim, o alargamento do acervo lexical foi feito ao serviço da realização da tarefa final, como preconiza o ELBT. Os alunos tinham ainda de formular cinco frases úteis, no máximo, as que Ihes parecessem as mais importantes. Por fim, teriam de preparar um diálogo prototípico, que, embora não tendo um limite de palavras, deveria corresponder a uma conversa com início, meio e fim. Num texto clássico de Bardovi-Harlig (1996), em que se equaciona a relação entre a Pragmática e ensino de línguas, são dados exemplos de "conversas" em que os interlocutores não se cumprimentam nem se despedem, porque não há qualquer cuidado dos docentes em torná-las verosímeis e aproximá-las de interações reais.

$\mathrm{Na}$ aula 10, depois de ser retomada a atividade de interação em diferentes serviços, com uma reunião de cada grupo, os estudantes tiveram de fazer a dramatização, com os respetivos grupos, de uma situação do mesmo âmbito já trabalhado, mas diferente do diálogo modelo redigido anteriormente. Esta dramatização contou com um curto tempo de preparação prévia. Em contrapartida, todo o trabalho que vinha sendo feito conduzia, no fundo, à preparação desta tarefa. De referir que o grupo da situação a) selecionou uma sapataria.

Durante as dramatizações, todos os alunos deveriam estar atentos a aspetos a comentar, sobretudo do ponto de vista pragmático, de adequação discursiva. Já a professora registou questões linguísticas, tendo, para as menos conseguidas, selecionado alguns aspetos a abordar na aula 11, sob a forma de uma ficha de remediação de erros, ou de melhoramento da produção e da interação orais.

No final das dramatizações, houve comentário em grande grupo, sobre aspetos pragmáticos das interações. Como trabalho de casa, os alunos tiveram de aperfeiçoar o documento inicial sobre as situações de interação que cada grupo tinha trabalhado e enviá-lo à professora, para posterior correção. Os documentos foram distribuídos à turma, já corrigidos pela professora, na aula seguinte (a aula número 11).

Podemos ver, nos anexos 1 e 2, a título de exemplo, o resultado da ficha sobre a ida ao restaurante, depois de corrigida, assim como a ficha de remediação de erros, respetivamente. 
CARVALHO, Ângela; Duarte, Isabel Margarida - Interação oral em Português Língua Estrangeira: preparação significativa a partir de necessidades comunicativas

Para lá da tarefa: implicar os estudantes na aprendizagem de línguas estrangeiras no ensino superior. Porto: FLUP, 2019, pp. 116-134 DOI: https://doi.org/10.21747/9789898969217/paraa6

\section{3 - Algumas reflexões sobre a experiência}

Justamente porque as situações partiram das necessidades dos alunos, encontradas depois da reflexão que eles próprios fizeram, a motivação foi visível. Por exemplo: alguns dos elementos do grupo que preparou o diálogo sobre a ida ao cabeleireiro foram realmente ao cabeleireiro, o que aconteceu também com os estudantes do grupo da ida ao restaurante. Isto revela que as situações correspondiam a necessidades dos alunos, que eles estavam motivados para o projeto, que compreenderam que a interação com nativos é essencial para melhorarem o seu desempenho oral e que procuraram construir diálogos com verosimilhança discursiva, recolhendo exemplos de contextos reais. Por outro lado, o facto de se terem efetivamente deslocado ao cabeleireiro ou ao restaurante, criou a necessidade de os alunos interagirem oralmente para narrarem, aos colegas, a sua experiência nos estabelecimentos comerciais em causa (ex. cabeleireiro). Além disso, justificou, em alguns casos, a ânsia de contacto e interação com falantes nativos "porque tinham de fazer um trabalho para as aulas de português".

Os alunos com mais dificuldades no curso tiveram um melhor desempenho nas dramatizações do que seria expectável, dadas as referidas dificuldades. Todos leram/estudaram, com curiosidade e motivação, o resultado do trabalho dos colegas.

No entando, as alunas que abordaram a situação a), no momento da performance quiseram arriscar menos, talvez precisamente pelo seu perfil muito dedicado ao estudo da língua e ao desejo de obtenção de uma nota final de curso muito satisfatória, mantendo-se fiel ao diálogo que tinham criado, não cumprindo o solicitado. Esta opção revelou-se fatal para o sucesso da tarefa, dado que as alunas, ao estarem mais concentradas em reproduzir um discurso memorizado perderam espontaneidade e fluência e cometeram erros linguístico por esquecimento do "roteiro", tendo, inclusivamente, sido, por vezes, incoerentes. Como evitar este comportamento linguístico dos alunos é uma questão a equacionar para futuras experiências.

Depois de já concluído o projeto, pensámos que a correção do trabalho poderia ter sido feita de outra forma, mais centrada nos estudantes, sem ter sido logo a professora a corrigir a versão final. Numa próxima ocasião, tentaremos que, em grupos, sejam os próprios aprendentes a detetar as falhas, ou a encontrar soluções comunicativas e linguísticas mais adequadas para cada situação, de modo a aumentarmos a autonomia e a capacidade de autocorreção dos estudantes. Note-se ainda que considerámos que o material resultante desta tarefa é passível de ser usado como material didático no nível $A$, o que será experimentado por nós futuramente. 
CARVALHO, Ângela; Duarte, Isabel Margarida - Interação oral em Português Língua Estrangeira: preparação significativa a partir de necessidades comunicativas

Para lá da tarefa: implicar os estudantes na aprendizagem de línguas estrangeiras no ensino superior. Porto: FLUP, 2019, pp. 116-134 DOI: https://doi.org/10.21747/9789898969217/paraa6

\section{4 - Descrição refletida da segunda tarefa proposta}

Após a unidade didática sobre as profissões tradicionais, já mencionada no ponto 2 , no fim da aula 7, foram enviadas por email aos alunos as instruções (anexo 3) para a realização de um trabalho de projeto relacionado com o mesmo tema e intitulado "Profissões tradicionais no Porto". Na aula seguinte, a professora explicou as referidas instruções, para garantir a sua boa compreensão e indicou os elementos constituintes de cada grupo de trabalho. A constituição dos grupos ficou a cargo da professora, de modo a tentar garantir o maior equilíbrio possível entre os diversos elementos. Acrescenta-se ainda que os grupos de trabalho oscilavam entre os 2 e 3 elementos.

Todos os alunos teriam de preparar uma exposição oral e apresentá-la entre as aulas 27 e 28. O tema específico deveria ser escolhido por cada grupo, mas respeitando sempre o tema genérico proposto.

Com este trabalho, pretendeu-se que os alunos aprendessem mais sobre aspetos da cultura portuguesa, nomeadamente através do contacto com falantes nativos que falam de forma diversificada e, eventualmente, de variedades diatópicas e diastráticas diferentes da norma padrão do português europeu (PE). Além disso, esperava-se que os alunos conseguissem fazer pesquisas, isto é, retirar informação relevante de textos, processar e transmitir informação em português, assim como interagir com os seus colegas e com falantes nativos. Finalmente, num momento de mutação do perfil da cidade do Porto, pretendeu-se dar a conhecer atividades tradicionais, algumas delas em risco de desaparecimento, bem como incentivar a respetiva valorização. Os alunos foram encorajados a solicitar orientação na realização do trabalho à professora regente, assim com às professoras estagiárias que acompanhavam a turma.

As instruções apresentadas aos estudantes, constantes no anexo 3, contemplavam os seguintes aspetos: apresentação global do trabalho e dos seus objetivos, descrição das atividades previstas e do processo, avaliação (critérios e pontuações) e outras informações (nomeadamente que a apresentação oral de cada grupo seria filmada e disponibilizada aos aprendentes e que estes teriam de fazer uma autoavaliação do seu desempenho, apoiada nos critérios de avaliação apresentados). Foi ainda solicitado que cada grupo selecionasse até 1 minuto da conversa tida com o profissional entrevistado e transcrevesse o excerto escolhido. Dado que teriam de comentar aspetos linguísticos relacionados com o caráter espontâneo da conversa, aconselhou-se que a transcrição se debruçasse sobre uma sequência rica desse ponto de vista. O trabalho de transcrição, embora tenha um grau de dificuldade alta, é muito útil por exigir uma escuta 
CARVALHO, Ângela; Duarte, Isabel Margarida - Interação oral em Português Língua Estrangeira: preparação significativa a partir de necessidades comunicativas

Para lá da tarefa: implicar os estudantes na aprendizagem de línguas estrangeiras no ensino superior. Porto: FLUP, 2019, pp. 116-134 DOI: https://doi.org/10.21747/9789898969217/paraa6

atenta e repetida, que é feita em busca do sentido e, portanto, de forma intrinsecamente motivada.

Os profissionais escolhidos pelos estudantes foram: barbeiro da baixa do Porto, vendedora de galinhas e coelhos vivos do Mercado Municipal de Matosinhos, rendilheira de bilros do Museu das Rendas de Bilros de Vila do Conde, peixeira do Mercado Municipal de Matosinhos e vendedora de fruta de uma frutaria na baixa do Porto.

De notar que alguns dos alunos passaram a frequentar os serviços e / ou os estabelecimentos selecionados ${ }^{2}$, deste modo prolongando as ocasiões de interação oral espontânea com os interlocutores, falantes nativos de PE, de variedades que podemos considerar populares.

A propósito destes trabalhos e motivados por eles, os estudantes criaram um grupo WhatsApp, onde foi incluída também a docente, o que os "obrigou" a escrever em português. Assim se testemunha que um projeto motivador e que envolva os aprendentes tem inesperados efeitos colaterais que potenciam a aprendizagem da língua-alvo, alargando os momentos em que os alunos interagem em português, de forma significativa.

No anexo 4 encontra-se o exemplo do minuto selecionado pelo grupo da rendilheira de bilros com a respetiva transcrição. Com a gravação e a transcrição, podemos fazer o levantamento do que for mais interessante do ponto de vista pragmático-discursivo: presença abundante de deixis de lugar característica de um discurso situado (aqui, isto, nesta), marcas de um discurso produzido sem planeamento prévio, como frases e palavras incompletas ("mas nal'" talvez por "mas nalgumas"), repetições, hesitações e autocorreções (somos quatro, cinco, quatro), pausas preenchidas (ee portanto), marcadores discursivos (prontos, não é?, portanto, pois), uso de diminutivos, sinais de assentimento (humhum), betacismo (berdade) e outras marcas fonéticas do falar nortenho.

\section{5 - Algumas conclusões}

Os exemplos brevemente apresentados neste texto visam testemunhar um percurso pedagógico com sentido e motivador, em que as tarefas se sucederam de modo a culminarem num miniprojeto final. Esse percurso partiu da perceção dos alunos sobre

\footnotetext{
2 Uma aluna que trabalhou sobre o barbeiro, voltou ao seu estabelecimento para the mostrar o documento em PowerPoint com a respetiva apresentação e levou com ela o namorado para ir lá cortar o cabelo, mandando foto para o grupo WhatsApp em que a turma e a docente partilhavam informações, fotografias, vídeos e comentários em português.
} 
CARVALHO, Ângela; Duarte, Isabel Margarida - Interação oral em Português Língua Estrangeira: preparação significativa a partir de necessidades comunicativas

Para lá da tarefa: implicar os estudantes na aprendizagem de línguas estrangeiras no ensino superior. Porto: FLUP, 2019, pp. 116-134 DOI: https://doi.org/10.21747/9789898969217/paraa6

as suas próprias necessidades comunicativas, e procurou fomentar momentos variados de interação oral. Tais momentos não dispensaram, obviamente, a estruturação de conhecimentos gramaticais e linguísticos, a cargo da docente. A língua foi usada para a concretização das diferentes propostas de trabalho em grupo, dentro mas também fora da aula, tendo sido incentivadas quer a autonomia quer a colaboração interpares.

No futuro, pretendemos aperfeiçoar o percurso, confrontando alguns dos diálogos criados pelos alunos, com interações reais gravadas e transcritas, cobrindo as mesmas situações comunicativas. Os aprendentes poderão, em consequência, contactar com conversas autênticas e ver em que se afastam e aproximam dos textos por si produzidos.

O facto de os estudantes enviarem gravações vídeo à docente, por WhatsApp, enquanto se encontravam fora da aula, durante a realização do projeto, testemunha o entusiasmo com que o encararam e, simultaneamente, permitiu-nos verificar que conversavam e conviviam em português fora do tempo letivo, o que é outro objetivo que esta metodologia ajuda a alcançar.

\section{Referências bibliográficas}

Bardovi-Harlig, K. (1996). Pragmatics and Language Teaching: Bringing Pragmatics Bringing Pragmatics and Pedagogy Together. In: Bouton, Lawrence F., Ed. Pragmatics and Language Learning. Monograph Series Volume 7, 21-39.

Byram, M. (1997). Teaching and assessing intercultural communicative competence. Clevedon: Multilingual Matters.

Castro, C. \& Grosso, M. J. (2017). Ensino de Línguas Baseado em Tarefas - Da Teoria à Prática. Lisboa: Lidel.

Estaire, S. \& Zanón, J. (1990). El diseño de unidades didácticas en L2 mediante tareas: principios y desarrollo. CL \& E: Comunicación, lenguaje y educación, 7-8, 55-89

Nunan, D. (2004). Task-based language teaching. Cambridge: Cambridge University Press.

Perrenoud,Ph. (1995). Ofício de aluno e sentido do trabalho escolar. Porto: Porto Editora.

Perrenoud, Ph. (1999). Apprendre à l'école à travers des projets: pourquoi ? Comment? Faculté de psychologie et des sciences de l'éducation, Université de Genève.

http://www.unige.ch/fapse/SSE/teachers/perrenoud/php main/php 1999/1999 17.rtf 
CARVALHO, Ângela; Duarte, Isabel Margarida - Interação oral em Português Língua Estrangeira: preparação significativa a partir de necessidades comunicativas

Para lá da tarefa: implicar os estudantes na aprendizagem de línguas estrangeiras no ensino superior. Porto: FLUP, 2019, pp. 116-134 DOI: https://doi.org/10.21747/9789898969217/paraa6

Pinto, J. (2011). O ensino de línguas baseado em tarefas e o foco na forma: contributos para uma didáctica do PL2 em Cabo Verde. Linguarum Arena, 2, 27-41.

Richards, J. C., \& Rodgers, T. S. (2001). Approaches and Methods in Language Teaching. Cambridge: Cambridge University Press.

Vera, A., \& Blanco, M. (2014). Cuestiones de Pragmática en la enseñaza del español como 2/L. Madrid: Arco Libros.

Vygotsky, L. S. (1978). Mind in Society - The Development of Higher Psychological Processes. Cambridge MS: Harvard University Press.

Matos, C. (2018). A curta-metragem como recurso didático na aula de português língua estrangeira. Relatório de estágio no âmbito do Mestrado em Português Língua Segunda/ Língua Estrangeira. Porto: Faculdade de Letras da Universidade do Porto. 


\section{Anexos}

\section{Anexo 1}

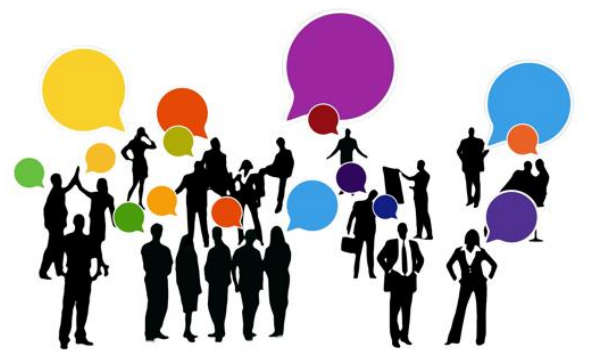

\section{Interações em serviços Restaurante}

Vocabulário específico

- a reserva: qualquer coisa que se mantém guardada (no caso do restaurante, uma mesa).

- a entrada: a comida que comemos em primeiro lugar e que é menor do que o prato principal.

- o prato principal: a comida central de um almoço ou jantar.

- a sobremesa: a comida doce (ou fruta) que comemos depois do prato principal.

- a/o empregado/a de mesa: a pessoa que trabalha na sala e serve às mesas (dá os pratos, anota os pedidos de comida).

- a/o cozinheiro/a: a pessoa que prepara a comida no restaurante.

- o menu/a ementa: o objeto onde estão escritas as bebidas e a comida que é possível pedir.

- a conta: o valor que o cliente tem de pagar pela comida e bebidas que consumiu.

- a gorjeta: o dinheiro que o cliente dá ao empregado de mesa(/cozinheiro) além do valor da conta. 
CARVALHO, Ângela; Duarte, Isabel Margarida - Interação oral em Português Língua Estrangeira: preparação significativa a partir de necessidades comunicativas

Para lá da tarefa: implicar os estudantes na aprendizagem de línguas estrangeiras no ensino superior.

Ações principais

- reservar uma mesa

- pedir um prato

- comer no restaurante

- beber (um copo de água, de vinho)

- brindar

- $\quad \operatorname{provar}$ (um prato, um molho)

- pagar a conta

- dar uma gorjeta

Frases úteis

- Tem mesa para duas pessoas?

- Qual é a especialidade do chefe?

- Qual é o prato do dia?

- Por trazer a conta, por favor?

- Posso pagar com cartão de crédito?

Diálogo modelo

A - Boa noite, quantas pessoas vão ser para jantar?

B - Boa noite, somos duas.

A - Podem sentar-se onde quiserem. Já trago a ementa.

A - Já sabem o que vão querer?

B - Já. Pode ser um arroz de marisco para duas e para beber dois finos, se faz favor.

A - Vão querer alguma sobremesa?

B - Não, obrigada. Só dois cafezinhos, por favor, e já pode trazer a conta.

A - Estava tudo bom?

B - Estava ótimo! Posso pagar com cartão de crédito?

A - Com certeza. Se gostaram da comida, voltem sempre.

B - Obrigada, então até à próxima!

\section{Anexo 2}


CARVALHO, Ângela; Duarte, Isabel Margarida - Interação oral em Português Língua Estrangeira: preparação significativa a partir de necessidades comunicativas

Para lá da tarefa: implicar os estudantes na aprendizagem de línguas estrangeiras no ensino superior. Porto: FLUP, 2019, pp. 116-134 DOI: https://doi.org/10.21747/9789898969217/paraa6

\section{Ficha de correção de erros}

1. Leia as frases que se seguem e:

1.1 identifique os erros e

1.2 corrija-os.

A. Um lavado e um corte costa $10 €$. (2 erros)

B. O quarto do hotel tem banheiro privado com janela afora para arejar? Não gosto de tomar ducha em espaços partilhados. (3 erros)

C. Tu tem de me dizer donde é o restaurante de o leitão de que falaste no outro dia. (3 erros)

D. Precisava de cortar o cabelo hoy. Vou escrivir um mensagem ao cabeleireiro. (3 erros)

E. Gostaria ver dessas sandalías de talão alto que tem aí. Gosto más. (5 erros)

F. Pronto? Soy João e estou a ligar para vossa agência de arrendar porque vi umo anúncio de um apartamento com dos quartos perfecto para mim. Queria mais informações sobre este T1 plus 1 (9 erros) 
CARVALHO, Ângela; Duarte, Isabel Margarida - Interação oral em Português Língua Estrangeira: preparação significativa a partir de necessidades comunicativas

Para lá da tarefa: implicar os estudantes na aprendizagem de línguas estrangeiras no ensino superior.

\section{Anexo 3}

\section{Introdução}

- Todos os alunos terão de preparar uma exposição oral e apresentá-la entre os dias 4 e 5 de junho de 2018 (datas provisórias). O trabalho vai ser realizado em grupo de três elementos durante o 20 semestre e apresentado no fim do semestre. Os grupos são formados pela professora de forma a terem uma composição o mais equilibrada possível. O tema específico deverá ser escolhido por cada grupo e tem de respeitar o tema genérico: Profissões tradicionais no Porto.

- Com este trabalho pretende-se que os alunos aprendam mais sobre aspetos da cultura portuguesa, nomeadamente através do contacto com falantes nativos que falam de forma diversificada e, eventualmente, diferente da norma padrão do português.

- Além disso, espera-se que os alunos consigam fazer pesquisas, processar e transmitir informação em português, assim como interagir com os seus colegas e com falantes nativos.

- Finalmente, num momento de mutação do perfil da cidade do Porto, pretendese dar a conhecer e incentivar a valorização de atividades tradicionais, algumas delas em risco de desaparecimento.

- Os alunos são incentivados a solicitar às professoras orientação na realização do trabalho.

\section{Tarefa apresentada por atividades}

- Escolha em grupo de uma profissão e de um profissional/negócio concreto que se enquadre na temática geral do trabalho

- Pesquisa sobre o tema

- Realização de trabalho de campo (visita e diálogo com o profissional, gravação da conversa e transcrição de cerca 1 minuto da conversa)

- Apresentação aos colegas da profissão, das impressões e reflexões resultantes da visita e destaque de algumas expressões linguísticas que consideraram relevantes. A apresentação deve demorar entre 10 minutos, no mínimo, e 15 minutos, no máximo.

- Resposta, depois da apresentação, a perguntas dos colegas e das professoras. 
CARVALHO, Ângela; Duarte, Isabel Margarida - Interação oral em Português Língua Estrangeira: preparação significativa a partir de necessidades comunicativas

Para lá da tarefa: implicar os estudantes na aprendizagem de línguas estrangeiras no ensino superior. Porto: FLUP, 2019, pp. 116-134 DOI: https://doi.org/10.21747/9789898969217/paraa6

\section{Processo}

- definir o tema com rigor

- informar a professora do tema

- pesquisar sobre o tema, recorrendo a diversos materiais e recursos em língua portuguesa

- preparar e realizar a visita ao profissional

- gravar da conversa

- distinguir a informação relevante da acessória

- compilar e organizar dados, informações, imagens, etc.

- Transcrever cerca de 1 minuto da conversa

- criar uma apresentação final (em PowerPoint), clara e organizada, correta ortograficamente, identificando fontes consultadas

- apresentar o trabalho oralmente com clareza e fluência, prestando atenção à pronúncia e gramática

- responder claramente a todas as questões dos colegas, estando recetivo ao diálogo sobre o trabalho realizado

\section{Avaliação}

Apresentação Oral - (4/20 da nota final) - 100\%

Durante a apresentação:

Respeitar o tempo da apresentação (4\%)

- Apresentar um aspeto pertinente para o tema do trabalho proposto (4\%)

-Apresentar o trabalho de forma apelativa (8\%)

-Apresentar o tema de forma clara e organizada (16\%)

$\square$ Referir (por escrito e, eventualmente, de forma oral) as fontes pesquisadas (3\%)

UUtilizar vocabulário adequado (9\%)

DPronunciar corretamente as palavras (9\%)

Uusar estruturas frásicas bem construídas $(9 \%)$

Ter fluência no discurso (9\%)

DApresentar de forma refletida aspetos linguísticos relevantes da conversa (7\%)

\section{Depois da apresentação:}

Responder às questões satisfatoriamente (10\%)

Colocar questões pertinentes aos colegas (6\%)

Autoavaliar-se de forma crítica, através da resposta a um questionário (6\%) 
CARVALHO, Ângela; Duarte, Isabel Margarida - Interação oral em Português Língua Estrangeira: preparação significativa a partir de necessidades comunicativas

Para lá da tarefa: implicar os estudantes na aprendizagem de línguas estrangeiras no ensino superior. Porto: FLUP, 2019, pp. 116-134 DOI: https://doi.org/10.21747/9789898969217/paraa6

Avaliação

\title{
Apresentação Oral - (1/20 da nota final) \\ Transcrição de cerca de 1 minuto da conversa
}

\section{Datas}

- Informar a professora sobre o tema até dia 2 de abril de 2018

\begin{abstract}
As gravações das conversas (completas) deverão ser entregues juntamente com a transcrição de cerca de 1 minuto selecionado da conversa.

As apresentações serão gravadas em suporte vídeo e posteriormente disponibilizadas aos alunos como base à reflexão crítica sobre a apresentação oral (preenchimento de uma ficha de autoavaliação - entregar até dia 8 de junho de 2018).
\end{abstract}


CARVALHO, Ângela; Duarte, Isabel Margarida - Interação oral em Português Língua Estrangeira: preparação significativa a partir de necessidades comunicativas

Para lá da tarefa: implicar os estudantes na aprendizagem de línguas estrangeiras no ensino superior. Porto: FLUP, 2019, pp. 116-134 DOI: https://doi.org/10.21747/9789898969217/paraa6

\section{Anexo 4}

\section{Link para o exemplo do minuto selecionado pelo grupo da rendilheira de bilros} https://drive.google.com/file/d/1uY4RkZO79WYZEik7GI5t_54yNeaVmap7/view?us=sharing

\section{Transcrição corrigida}

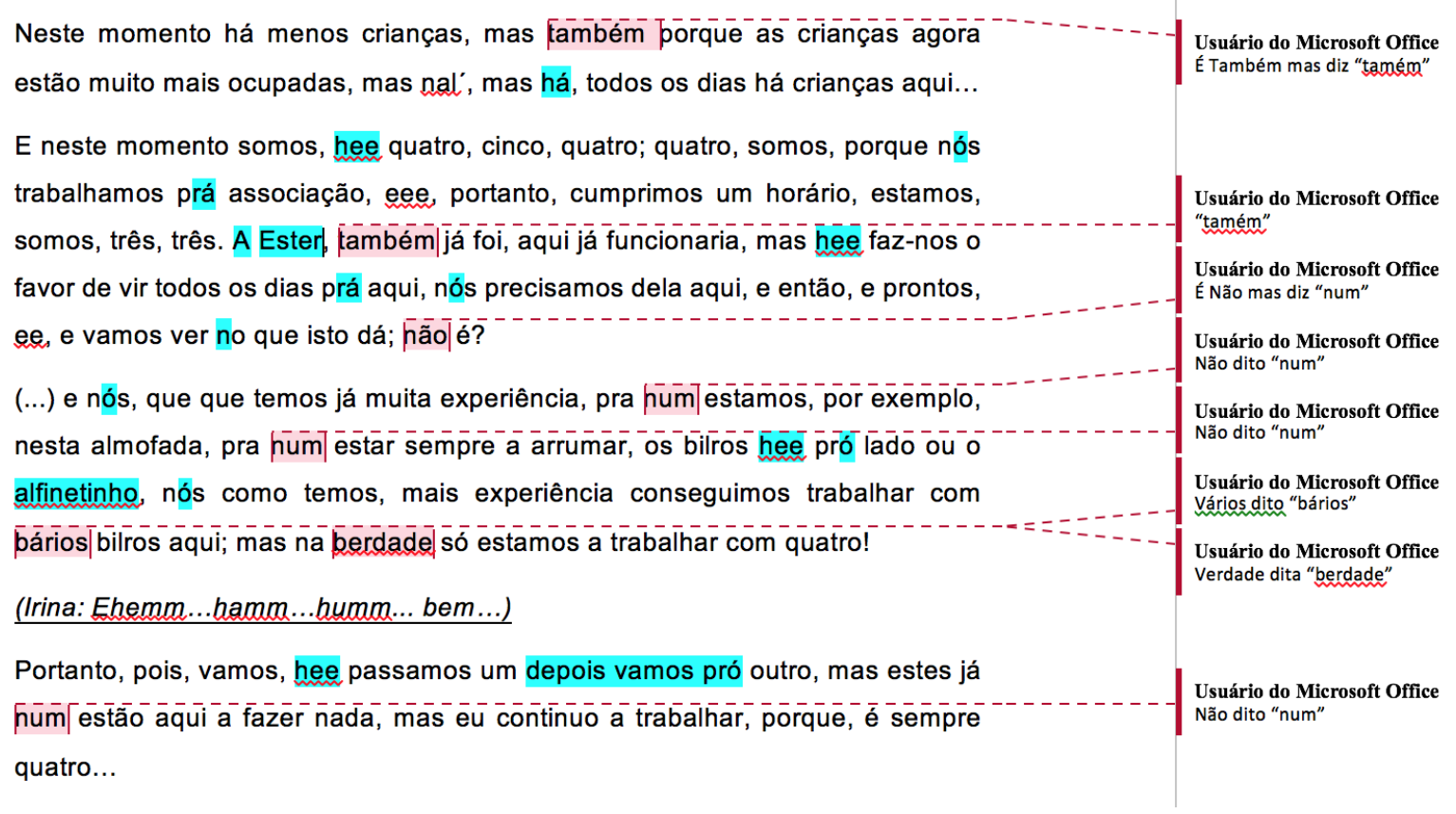

